\title{
ZnO nanostructured microspheres and grown structures by thermal treatment
}

\author{
JUN WANG*, SHUNXIAO ZHANG, JIA YOU, HUIJUN YAN, \\ ZHANSHUANG LI, XIAOYAN JING and MILIN ZHANG \\ School of Material Science and Chemical Engineering, Harbin Engineering University, Harbin 150001, P R China
}

MS received 9 October 2007; revised 11 June 2008

\begin{abstract}
Synthesis of flower-shaped $\mathrm{ZnO}$ nanostructures composed of $\mathrm{ZnO}$ nanosticks was achieved by the solution process using zinc acetate dihydrate, sodium hydroxide and polyethylene glycol-20000 (PEG-20000) at $180^{\circ} \mathrm{C}$ for $4 \mathrm{~h}$. The diameter of individual nanosticks was about $100 \mathrm{~nm}$. Detailed structure characterizations demonstrate that the synthesized products are wurtzite hexagonal phase, grown along the [001] direction. The infrared (IR) spectrum shows the standard peak of zinc oxide at $571 \mathrm{~cm}^{-1}$. Raman scattering exhibits a sharp and strong $E_{2}$ mode at $441 \mathrm{~cm}^{-1}$ which further confirms the good crystal and wurtzite hexagonal phase of the grown nanostructures.
\end{abstract}

Keywords. Nanostructures; zinc oxide; flower.

\section{Introduction}

During the past few years, attention has been focused on the one-dimensional (1D) nanostructure materials, such as nanowires and nanorods, because of both their fundamental importance and the wide range of their potential applications in nanodevices (Hu et al 1999; Xia et al 2003). In order to obtain nanowires or nanorods of the desired materials, various methods have been developed for the preparation of 1D nanostructures. These methods, including the vapour-phase transport process (Bai et al 1999; Chen and Yeh 2000; Wu and Yang 2000), chemical vapour deposition (Yazawa et al 1992), arc discharge (Choi et al 2000), laser ablation (Duan and Lieber 2000), solution (Trentler 1995; Holmes et al 2000), and a template-based method (Huang et al 2000; Li et al 2000), have been used extensively in synthesizing many inorganic nanocrystals, nanorods and nanowires.

Semiconducting oxide $\mathrm{ZnO}$ has wide and direct fundamental bandgap energy of $3.37 \mathrm{eV}$ with large exciton binding energy $(60 \mathrm{mV})$ and high mechanical and thermal stability. 1D $\mathrm{ZnO}$ nanostructures have been studied for optoelectronic nanodevice applications as a promising candidate for UV light-emitting diodes and laser diodes (Huang et al 2001a, b; Johnson et al 2001, 2002). To date, $\mathrm{ZnO}$ with different nanostructures, such as nanowires (or nanorods), nanobelts (nanoribbons) (Pan et al 2001; Yang et al 2002), comb-like nanowires array (Yan et al 2003), nanoneedles arrays (Park et al 2002), and nanorings (Kong et al 2004) have been successfully synthesized. For ex-

\footnotetext{
*Author for correspondence (junwang@hrbeu.edu.cn)
}

ample, single crystalline $\mathrm{ZnO}$ nanobelts and nanorings have been prepared by thermal evaporation $\mathrm{ZnO}$ powder. Using metal-organic chemical vapour deposition (MOCVD) method, vertically well-aligned $\mathrm{ZnO}$ nanoneedles on $\mathrm{Si}$ substrates also has been reported (Park et al 2005).

Recently, much effort has been focused on the fabrication of inorganic mesostructures by controlling the size, shape, crystal structure, and surface structure (Peng et al 2000), because these features contribute much to the variety in applications (Wang 2003). In this article, we introduce the formation of single-crystalline flower-shaped $\mathrm{ZnO}$. Their structure and morphology were characterized by X-ray diffraction (XRD), scanning electron microscopy (SEM) and transmission electron microscopy (TEM).

\section{Experimental}

Synthesis was carried out by solution process at $180^{\circ} \mathrm{C}$ using zinc acetate dihydrate, sodium hydroxide and PEG20000 as source materials. For the synthesis, equivalent volume zinc acetate dihydrate $(0.5 \mathrm{M})$ and sodium hydroxide $(5 \mathrm{M})$ were mixed to obtain solution A. $1 \mathrm{~g}$ PEG20000 was dissolved in $4 \mathrm{ml}$ of water by sonication to obtain solution B. The solution B was then added into $5 \mathrm{ml}$ solution A to obtain solution C. $55 \mathrm{ml} \mathrm{1-Octanol} \mathrm{was} \mathrm{added}$ to solution $\mathrm{C}$ under stirring at room temperature to obtain solution D. Then solution D was transferred to Teflonlined stainless steel autoclave which was then heated at $180^{\circ} \mathrm{C}$ for $4 \mathrm{~h}$ in an electric oven. The $\mathrm{ZnO}$ powder could be obtained after filtering, washing and drying. The white powder was examined in terms of their structure, chemical and optical properties. 

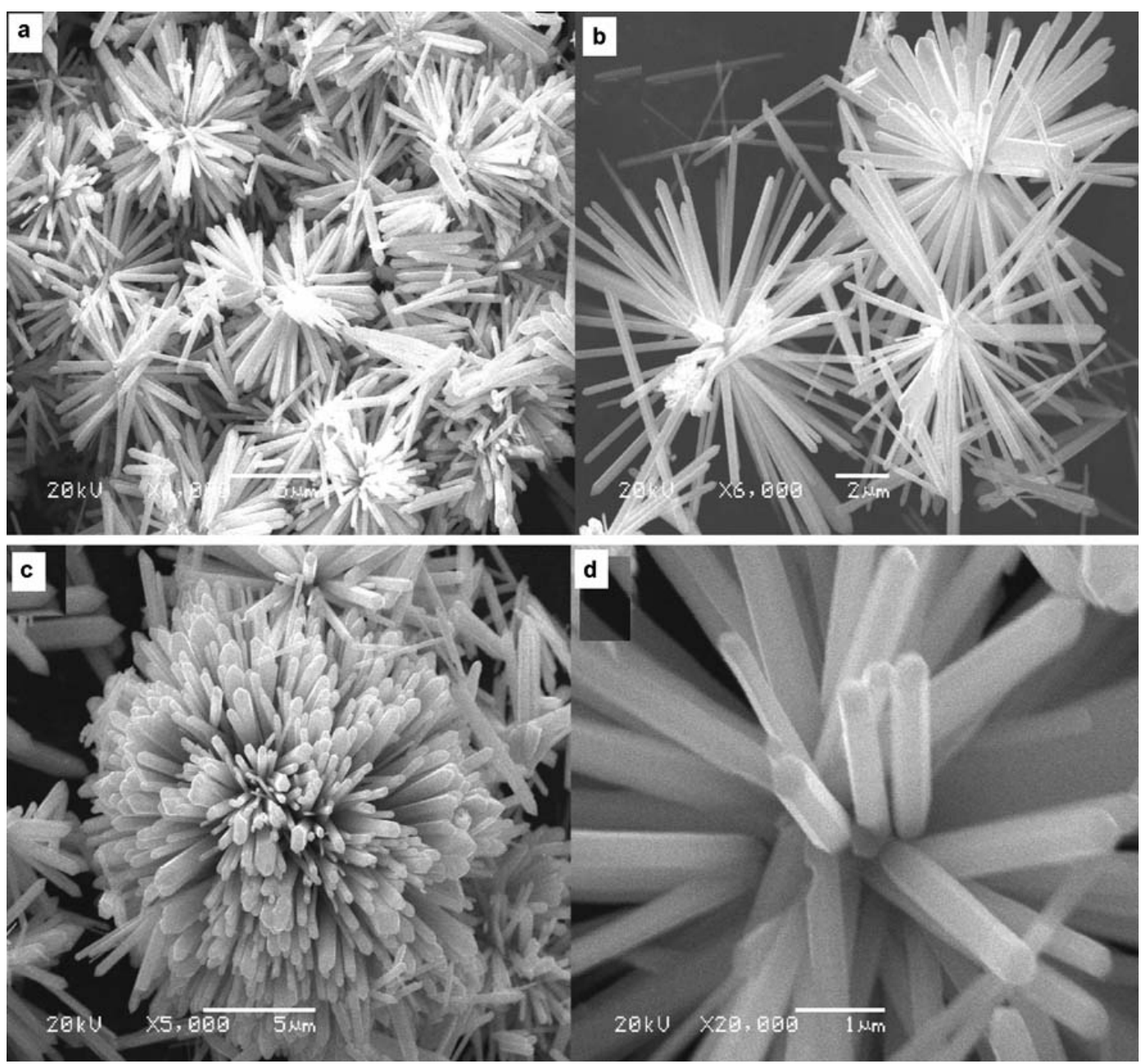

Figure 1. SEM images of $\mathrm{ZnO}$ : (a and $\mathbf{b}$ ) overall product morphology and ( $\mathbf{d}$ and $\mathbf{c}$ ) detailed view on an individual flower.

General morphology and detailed structure of $\mathrm{ZnO}$ were determined using scanning electron microscopy (SEM). For TEM measurements, $\mathrm{ZnO}$ powder was sonicated in ethanol for $30 \mathrm{~min}$. A copper grid was immersed in and taken out of the suspension and dried at room temperature. The structure and crystal phases were determined by X-ray powder diffractometer (XRD) with $\mathrm{CuK} \alpha$ radiation $(\lambda=$ $1.54178 \AA$ ) with Bragg angle ranging from $20-80^{\circ}$. The quality and composition of the synthesized sphereshaped $\mathrm{ZnO}$ nanostructures were characterized by the infrared (IR) spectroscopy in the range of $400-4000 \mathrm{~cm}^{-1}$. Optical properties were analysed by the Raman scattering.

\section{Results and discussion}

\subsection{Detailed structural characterization of sphere-shaped ZnO nanostructures}

Figures 1(a) and (b) show the low magnification FESEM images of $\mathrm{ZnO}$ nanostructures and figures $1(\mathrm{c})$ and (d)

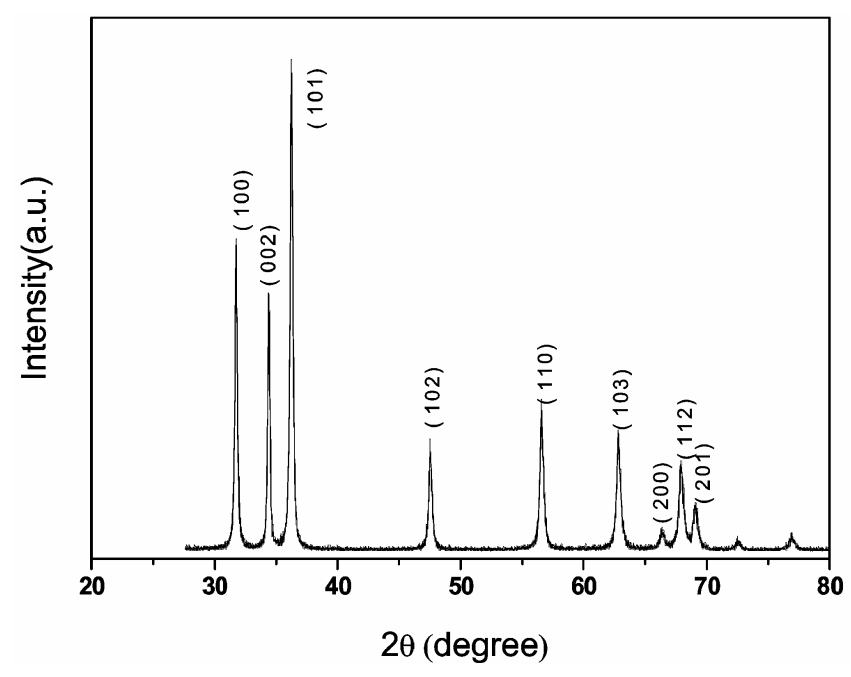

Figure 2. Typical X-ray diffraction (XRD) pattern synthesized nanostructure: the indexed peaks correspond to the wurtzite hexagonal phase.

present the high magnification images of the $\mathrm{ZnO}$ nanostructures. The images clearly reveal that the flower-shaped 

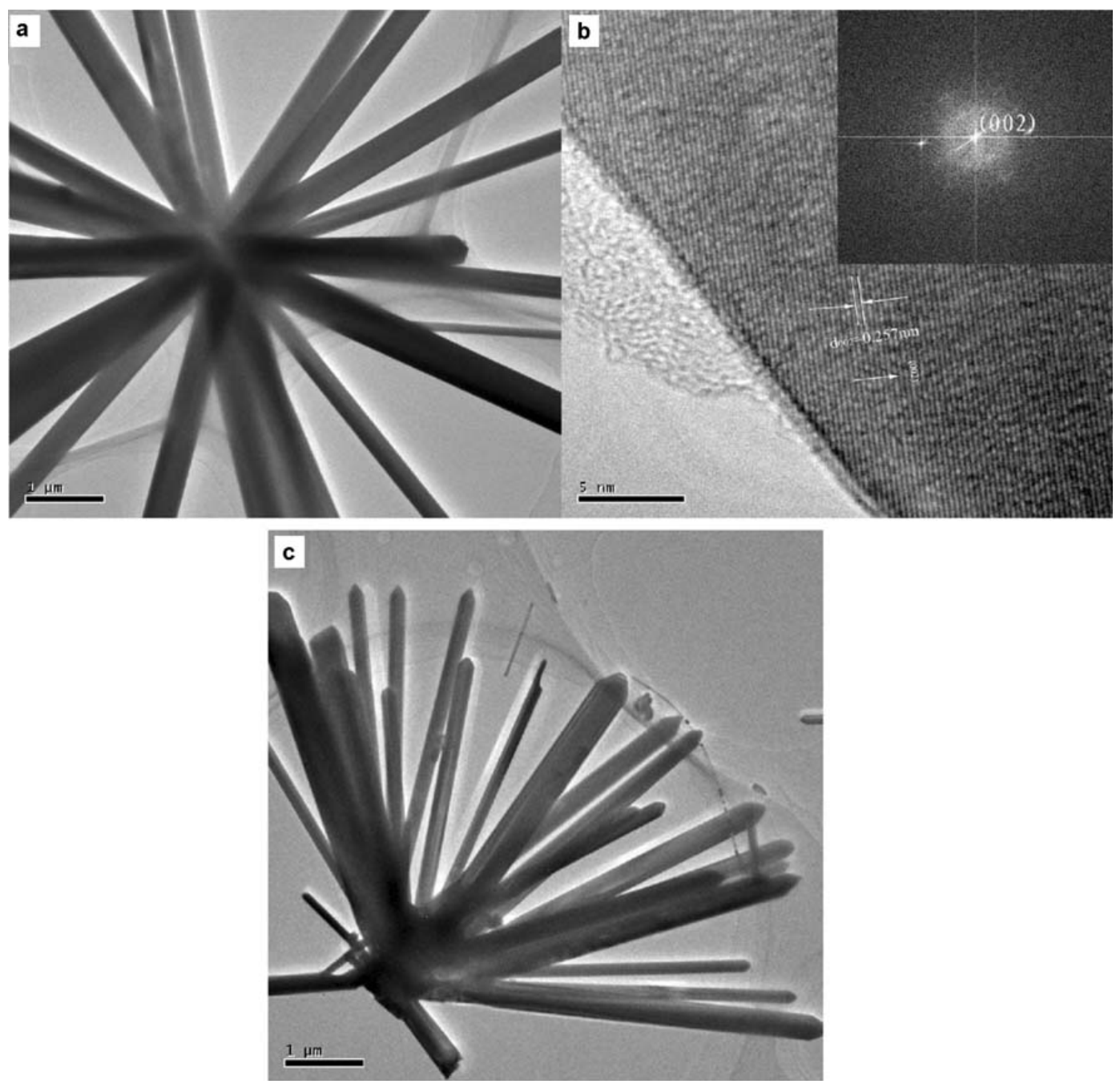

Figure 3. a. Low magnification TEM image of the grown ZnO nanosticks, b. HRTEM image showing the difference between two lattice fringes, which is about $0.257 \mathrm{~nm}$ and the corresponding FFT pattern (inset) is consistent with the HRTEM observation and $\mathbf{c}$. side elevation of the grown ZnO nanosticks.

structures are composed of hexagonal nanorods. Magnified image shows that flower-shaped structures are constituted by the accumulation of hexagonal $\mathrm{ZnO}$ nanosticks. The typical diameters of these individual nanosticks are in the range of 350-450 $\mathrm{nm}$ with a length of $1-2 \mu \mathrm{m}$. All the nanosticks are seen originating from a single centre arranging them in a spherical shape exhibiting flower-like morphologies. The size of full array of a flower-shaped structure is in the range of $10-15 \mu \mathrm{m}$.

Figure 2 presents the X-ray diffraction pattern of synthesized powder. All of the indexed peaks in the obtained spectrum are well matched with that of bulk $\mathrm{ZnO}$ (JCPDS Card No. 36-1451), which confirms that the synthesized powder is wurtzite hexagonal structures. No other peak related to impurities was detected in the spectrum within the detection limit of the X-ray diffraction. Additionally, higher intensity and narrower spectral width of $\mathrm{ZnO}$ peak, compared to other observed $\mathrm{ZnO}$ peaks in the spectrum affirms that the synthesized powders are pure $\mathrm{ZnO}$.

Further structure characterization was carried out by the transmission electron microscopy (TEM) equipped with the FFT setup. Figure 3(a) shows the low magnification TEM image of the $\mathrm{ZnO}$ nanosticks grown in the flowershaped structures. The $\mathrm{ZnO}$ nanosticks are clearly evident from this image. Figure 3(b) shows the high resolution transmission electron microscopy (HRTEM) image of nanosticks. The lattice spacing of $0.257 \mathrm{~nm}$ corresponds to the $d$ spacing of [002] crystal planes, confirming these crystals have a wurtzite structure and grown along the $c$ axis direction. The corresponding FFT pattern (inset in figure 3(b)) is consistent with the HRTEM observation.

The expected growth process of the flower-shaped $\mathrm{ZnO}$ nanostructures can be explained by the nature twines of PEG-20000 (figure 4). PEG-20000 is a non-ionic surface 


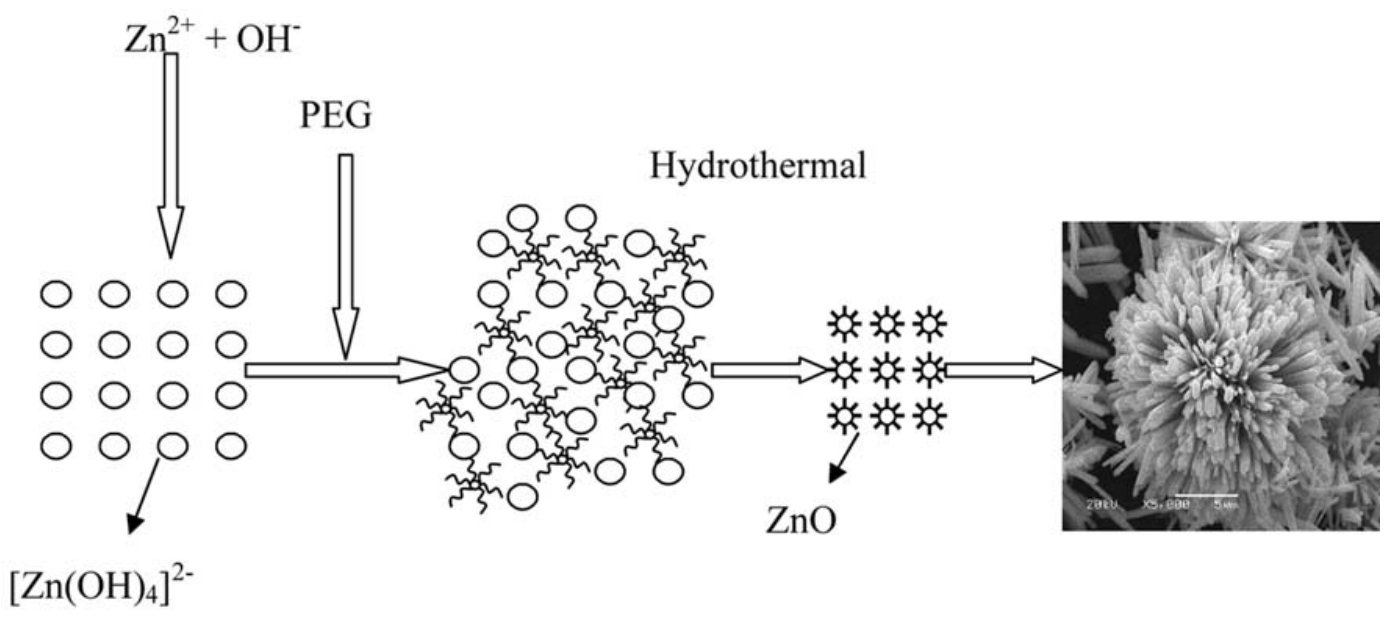

Figure 4. Illustration of the formation mechanism of flower-shaped $\mathrm{ZnO}$.

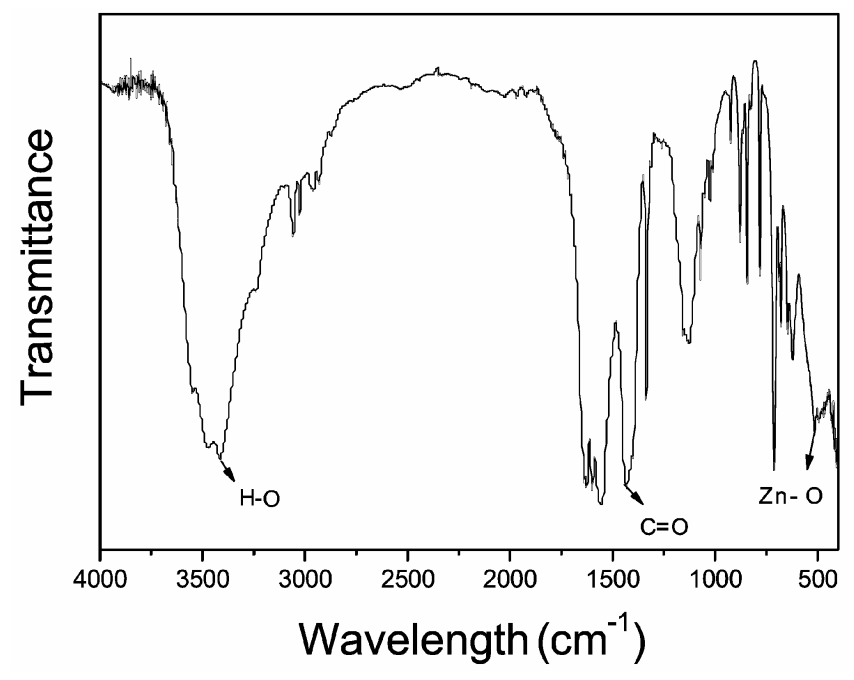

Figure 5. Typical IR spectrum of the synthesized nanostructure.

active agent, the oxygen atom which is on the long chains is the water affinity groups and bases, $-\mathrm{CH}_{2}-\mathrm{CH}_{2}-$ is the oil affinity groups and bases, there are water and oil affinity groups and bases on the long chains. The $\mathrm{Zn}^{2+}$ which is supplied by solvent act on the $\mathrm{O}$ which is on the chains of PEG-20000, as a result, reaction precursors will grow to certain direction, at the same time, PEG-20000 has the function of nature twines in the organic solution.

When equivalent volume zinc acetate dihydrate and sodium hydroxide were blended, the reaction precursors of $\left[\mathrm{Zn}(\mathrm{OH})_{4}\right]^{2-}$ were formed from the $\mathrm{Zn}^{2+}$ and $\mathrm{OH}^{-}$ions. Then the reaction precursors will enwind owing to the PEG-20000, then $\left[\mathrm{Zn}(\mathrm{OH})_{4}\right]^{2-}$ becomes flower-shaped due to the function of the PEG-20000. The reaction precursors of $\left[\mathrm{Zn}(\mathrm{OH})_{4}\right]^{2-}$ is extremely unstable, when heated up, it will decompose to form $\mathrm{ZnO}$ nuclei, the $\mathrm{ZnO}$ will grow along the direction of the PEG-20000. With the passage of time, the function of PEG-20000 will disappear, the flower-shaped $\mathrm{ZnO}$ will be formed from $\left[\mathrm{Zn}(\mathrm{OH})_{4}\right]^{2-}$ under hydrothermal condition. The transformation of equivalent volume zinc acetate dihydrate and sodium hydroxide into the $\mathrm{ZnO}$ crystals is through simple reactions

$$
\begin{aligned}
& \mathrm{Zn}^{2+}+2 \mathrm{OH}^{-} \rightarrow\left[\mathrm{Zn}(\mathrm{OH})_{4}\right]^{2-}, \\
& {\left[\mathrm{Zn}(\mathrm{OH})_{4}\right]^{2-} \rightarrow \mathrm{ZnO}+\mathrm{H}_{2} \mathrm{O}+2 \mathrm{OH}^{-} .}
\end{aligned}
$$

The composition and quality of the product were analysed by the IR spectroscopy. Figure 5 shows the IR spectrum which was acquired in the range of $400-4000 \mathrm{~cm}^{-1}$. The band at $571 \mathrm{~cm}^{-1}$ is correlated to zinc oxide (Lili et al 2006). The band at $3200-3600 \mathrm{~cm}^{-1}$ corresponding to $\mathrm{O}-\mathrm{H}$ mode of vibration and the stretching mode of vibration of $\mathrm{C}=\mathrm{O}$ is observed at $1430 \mathrm{~cm}^{-1}$.

\subsection{Optical properties of sphere-shaped $\mathrm{ZnO}$ nanostructures}

The optical properties of the synthesized flower-shaped $\mathrm{ZnO}$ nanostructure were observed by the Raman scattering measurement. The Raman spectra are sensitive to the crystal quality, structural defects and disorders of the grown products. With a wurtzite hexagonal, $\mathrm{ZnO}$ belongs to the $C_{6 V}^{4}$ with two formula units per primitive cell. The primitive cell includes two formula units in which all the atoms occupy the $2 b$ sites of the $C_{3 V}$ symmetry. Group theory predicts, at the $\Gamma$ point of the Brillouin zone, the existence of following optic modes: $\Gamma=A_{1}+2 B_{1}+E_{1}+$ $2 E_{2}$. The $A_{1}, E_{1}$ and $E_{2}$ modes are Raman active. Furthermore, the $A_{1}$ and $E_{1}$ are infrared active and splits into longitudinal optical (OP) components and transverse optical (TO) components (Damen et al 1966). Figure 6 shows the Raman spectrum of the synthesized powder. A sharp and strong peak at $441 \mathrm{~cm}^{-1}$ is observed which is attri- 


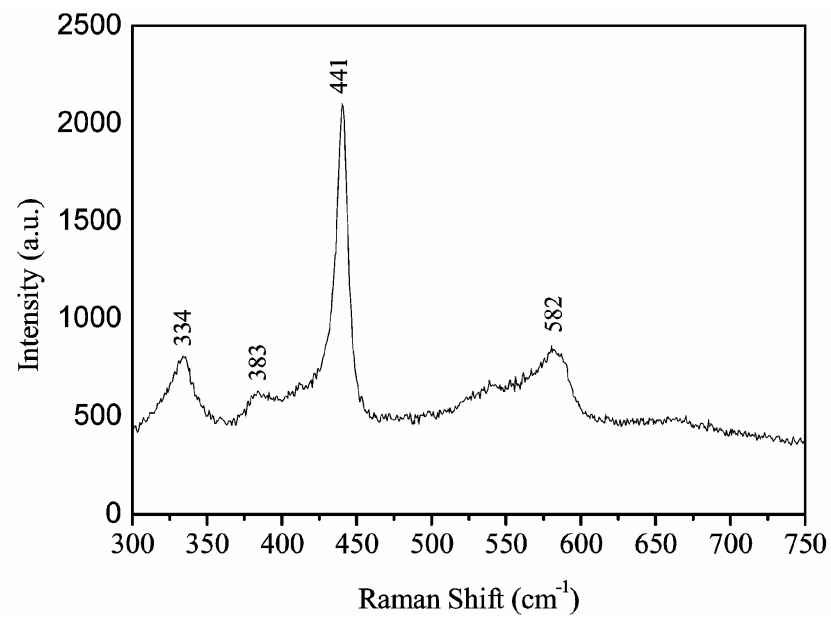

Figure 6. Typical Raman spectrum of the synthesized nanostructure.

buted to the optical phonon $E_{2}$ mode of the $\mathrm{ZnO}$ and a characteristic Raman active peak for the wurtzite hexagonal phase of $\mathrm{ZnO}$ (Xing et al 2003). Besides, two very small peaks at 335 and $383 \mathrm{~cm}^{-1}$ are also observed in the spectrum which are assigned to $E_{2 \mathrm{H}}-E_{2 \mathrm{~L}}$ (multi phonon process) and $A_{1 \mathrm{~T}}$ modes, respectively (Wahab et al 2007). Additionally, a very suppressed and short peak at $582 \mathrm{~cm}^{-1}$ is seen in the spectrum and attributed as $E_{1 \mathrm{~L}}$ mode (Vanheusden et al 1996; Rajalakshmi et al 2000). The origination of $E_{1 \mathrm{~L}}$ mode in the Raman scattering is because of the impurities and structural defects (oxygen vacancies and $\mathrm{Zn}$ interstitials) of the synthesized products. Therefore, the presence of high intensity $E_{2}$ mode with the suppressed and very short $E_{1 \mathrm{~L}}$ peak in the Raman scattering indicates that the synthesized sphere-shaped $\mathrm{ZnO}$ nanostructures are good in crystal quality and possesses the wurtzite hexagonal crystal structure.

\section{Conclusions}

Flower-shaped $\mathrm{ZnO}$ was synthesized by the solution process using equivalent volume zinc acetate dehydrate, sodium hydroxide and PEG-20000. Detailed structural characterizations demonstrate that the synthesized products have wurtzite hexagonal phase, and the flower-like $\mathrm{ZnO}$ crystals have a novel layered structure. We believe that the present method is simple, low-cost, and is expected to allow the large-scale production of other oxides with controllable morphologies.

\section{Acknowledgements}

We gratefully acknowledge the support of this research by the Key Technology R\&D program of Heilongjiang Province (no. TB06A05), Science Fund for Young Scholar of Harbin City (no. 2004AFQXJ038) and basic research fund for Harbin Engineering University (no. mzj07076).

\section{References}

Bai Z G, Yu D P, Zhang HZ, Ding Y, Gai X Z, Hang Q L, Xiong G C and Feng S Q 1999 Chem. Phys. Lett. 303311

Chen C C and Yeh C C 2000 Adv. Mater. 12738

Choi Y C et al 2000 Adv. Mater. 12746

Damen T C, Porto S P S and Tell B 1966 Phys. Rev. 142142

Duan X F and Leiber C M 2000 Adv. Mater. 12298

Holmes J D, Johnston K P, Doty R C and Korgel B A 2000 Science 2871471

Huang M H, Choudrey A and Yang P 2000 Chem. Commun. 12 1603

Huang M H, Mao S, Feick H, Yan H, Wu Y, King H, Weber E, Russo R and Yang P 2001a Science 2921897

Huang $\mathrm{MH}$, Wu Y, Feick H, Tran N, Weber E and Yang P 2001b Adv. Mater. 12113

Hu J T, Odom T W and Lieber C M 1999 Accounts Chem. Res. 32435

Johnson J C, Yan H, Schaller R D, Haber L H, Saykally R J and Yang P 2001 J. Phys. Chem. B105 11387

Johnson J C, Choi H J, Knusten K R, Schaller R D, Yang P and Saykally R J 2002 Nat. Mater. 1106

Kong X Y, Ding Y, Yang R and Wang Z L 2004 Science 303 1348

Li Y, Meng G W, Zhang L D and Phillipp F 2000 Appl. Phys. Lett. 762011

Lili W, Youshi W, Yuanchang S and Huiying W 2006 Rare Metals 2568

Pan Z W, Dai Z R and Wang Z L 2001 Science 2911947

Park J Y, Lee D J, Yun Y S, Moon J H, Lee B T and Kim S S 2005 J. Cryst. Growth 276158

Park W I, Kim D H, Jung S W and Yi G C 2002 Appl. Phys. Lett. 804232

Peng X G, Manna L, Yang W D, Wickham J, Scher E C, Kadavanich A and Alivisatos A P 2000 Nature 40459

Rajalakshmi M, Arora A K, Bendre B S and Mahamuni S 2000 J. Appl. Phys. 872445

Trentler T J, Hickman K M, Goel S C, Viano A M, Gibbons P C and Buhro W E 1995 Science 2701791

Vanheusden K, Seager C H, Warren W L, Tallant D R and Voigt J A 1996 J. Appl. Phys. 797983

Wahab R, Ansari S G, Kim Y S, Seo H K, Kim G S, Khang G and Shin H S 2007 Mater. Res. Bull. 421640

Wang Z L 2003 Nanowires and nanobelts: Materials, properties, and devices (Norwell, MA: Kluwer Academic Press) Vols I and II

Wu Y and Yang P 2000 Chem. Mater. 12605

Xia Y et al 2003 Adv. Mater. 15373

Xing Y J et al 2003 Appl. Phys. Lett. 831689

Yang P et al 2002 Adv. Funct. Mater. 12323

Yan H, He R, Johnson J, Law M, Saykally R J and Yang P 2003 J. Am. Chem. Soc. 1254728

Yazawa M, Koguchi M, Muto A, Ozawa M and Hiruma K 1992 Appl. Phys. Lett. 612051 